\title{
Cooperative Prevention Systems to Protect Rangelands From the Spread of Invasive Plants
}

\author{
By Kim Goodwin, Roger Sheley, James Jacobs, Shana Wood, Mark Manoukian, Mike \\ Schuldt, Eric Miller, and Sharla Sackman
}

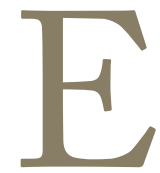

astern Montana is a vast region dominated by weed-free plains grassland. The protection of these prairies from the spread of invasive plants through weed prevention areas (WPAs) can preserve highquality rangelands for wildlife, livestock, and other ecosystem goods and services. Eastern Montana sustains a spacious region of native grasslands and shrublands (approximately $57,000 \mathrm{mi}^{2}$ ). The conservation of these rangelands has farreaching societal implications for long-term sustainability of ecosystem services and rural livelihoods.

Fortunately, most rangelands in eastern Montana still remain largely free of invasive weeds, or non-native plants that invade ecosystems and replace native plants. ${ }^{1}$ Preventing their spread into rangelands is critical because invasive weeds can alter ecosystem function, reduce habitat and grazing land, and cause damaging economic effects for land managers. ${ }^{2,3}$ Rangelands are susceptible to invasion due to frequent openings in plant cover, high light levels, and human activity that transports weeds and creates disturbance. Proactive strategies to counter invasion can keep rangelands weed-free, reducing the risk of environmental degradation, an outcome that could prove excessively costly to repair. Our objective is to illustrate the development and design of WPAs and the critical weed prevention actions that were developed in 12 WPAs in eastern Montana.

The protection of weed-free prairie yields societal benefits that are a public good whereby everyone benefits from a healthy environment. A large part of the prevention task, however, is convincing the public that although weed spread displays slow moving trends, and thus no obvious threats, it is a long-term crisis worthy of our best efforts. Prevention is promoted through local campaigns including 1) weed-free ranch signage and roadside kiosks designating WPAs, 2) messaging and monthly prevention tips to ranchers via local newspapers, 3) field tours to sites dominated by weeds, 4) passive monitoring networks, and 5) prevention symposiums to share information and encourage collaboration between researchers and land managers.

\section{Development and Design of Weed Prevention Areas}

It is critical to protect rangelands from the long-term impacts of invasive weeds, which are usually irreversible. We have made progress minimizing invasion by implementing WPAs as cooperative prevention systems in Montana. Unlike traditional cooperative weed management areas, which focus restoration and control efforts on land already dominated by weeds, ${ }^{4}$ WPAs prioritize less costly and more successful prevention strategies on weed-free rangelands having high conservation value with the goal of keeping them that way. ${ }^{3,5}$ WPAs protect rangelands from invasion by guiding proactive maintenance programs underpinned by prevention and monitoring strategies, designed and implemented by unified stakeholders.

Over the last five years, we developed 12 WPAs, encompassing about 5.5 million acres, as large-scale tests of their value and to provide insights on implementing cooperative prevention programs. These WPAs are located in eastern Montana (Fig. 1), east of the Continental Divide, a region largely represented by weed-free mixed-grass prairie. We delineated WPAs based on invasion threat, ecological status, and the number of landowners willing to support the development of invasive weed prevention programs. WPA boundaries follow section lines or visual markers, including waterways and roads. The size of WPAs (ranging from 150,000 to 450,000 acres) is based on the number and frequency of weed introductions. Smaller WPAs are located in areas where weeds are advancing since those areas require more intense management to find and remove invasions. WPAs are designated with roadside signs (Fig. 2) to publicize their ecological status and build public support for prevention.

A crucial step in the development of WPAs includes designing local prevention strategies. We held preliminary meetings with county weed departments, ranchers, and federal and state land managers to designate the WPA boundaries, prioritize the weeds likely to be introduced, and identify rancher leadership. Initial assessments and learning group discussions were conducted to design strategies in 


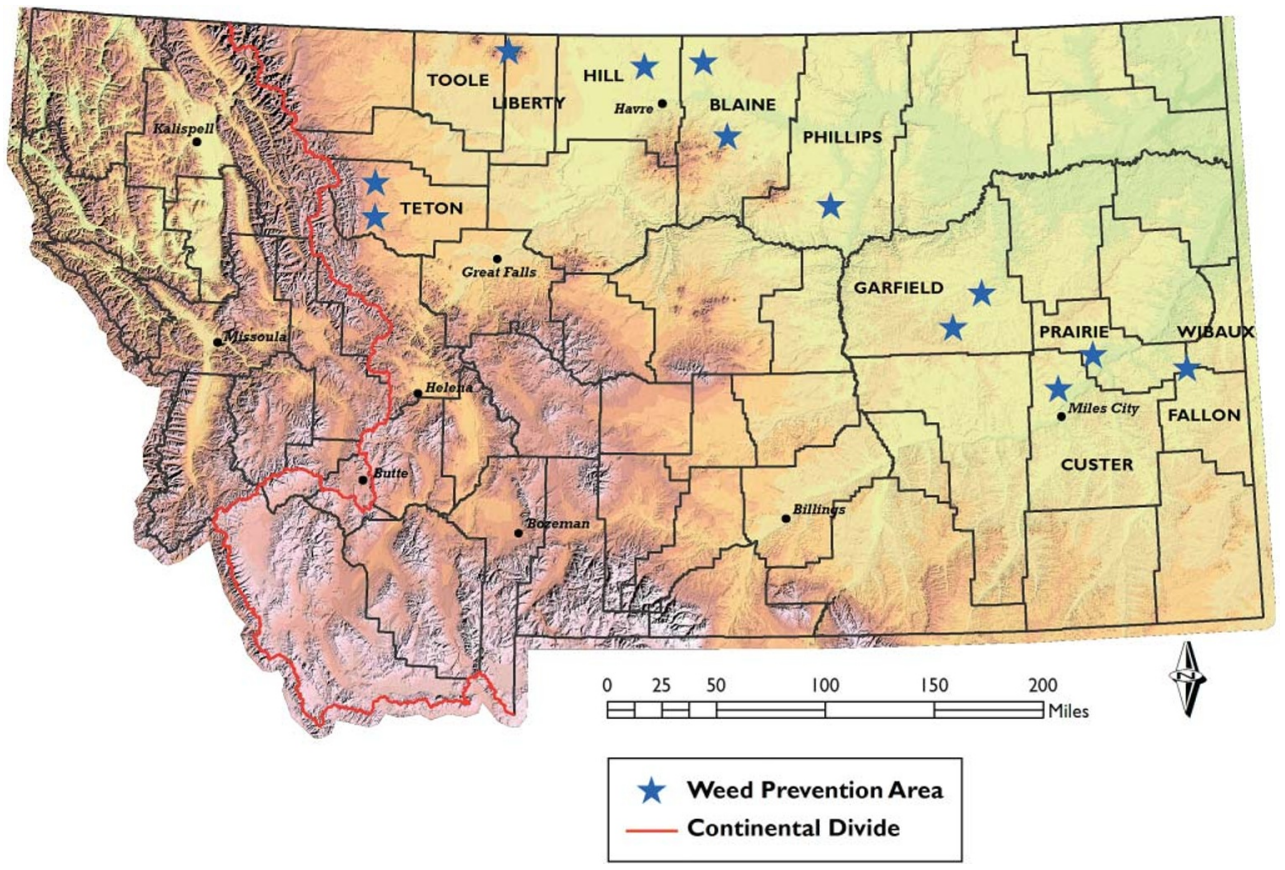

Figure 1. Locations of weed prevention areas in Montana.

terms of prevention constraints and potential solutions. We define weed prevention as those actions directed at weeds before eradication becomes infeasible.

Prevention actions are site specific and originate from ranchers to ensure project ownership and implementation. Based on these recommendations, WPA-specific plans are designed to coordinate prevention efforts. These plans include a two-page strategy accompanied by full-color fact sheets about the weeds threatening to invade the WPA. Weed alert fact sheets are published as Extension Service bulletins and include diagnostic and biological information, habitat requirements, and early control techniques.

\section{Weed Prevention Area Actions}

Prioritizing Weed Species

Determining which plants to target for prevention begins with stakeholder meetings. Field ecologists, county weed

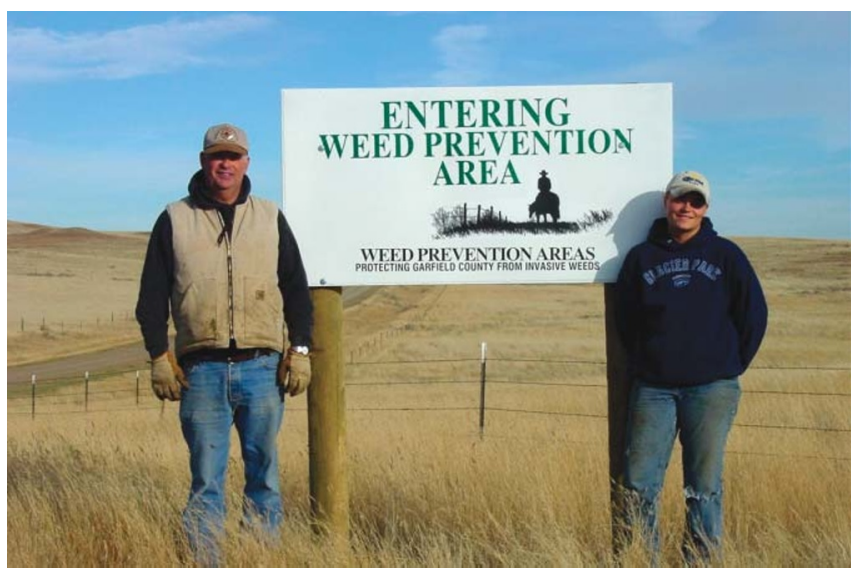

Figure 2. Weed prevention area signs mark weed-free areas and educate visitors. Photo: E. Miller, Garfield County Extension (MT). experts, and ranchers identify local weed threats on the basis of competitive abilities, ease of transport, and their presence in nearby counties. Several methods for prioritizing the most important weeds are used. Most WPA groups first consider the entire list of state declared noxious weeds. In Montana this designation is in response to a comprehensive analysis of the potential of an invasive plant to spread and impact native ecosystems. Adjacent county weed lists are also considered since they represent neighboring weed threats.

The priority noxious weeds threatening to invade new sites in eastern Montana largely include leafy spurge (Euphorbia esula), Dalmatian and yellow toadflax (Linaria dalmatica and Linaria vulgaris), saltcedar (Tamarix spp.), yellow starthistle (Centaurea solstitialis), rush skeletonweed (Chondrilla juncea), and spotted, diffuse, and Russian knapweed (Centaurea stoebe, Centaurea diffusa, and Rhaponticum repens). The invasiveness of the knapweeds, the impacts to grassland productivity, and the economic consequences to ranchers have made control of these plants, especially spotted knapweed, a priority in eastern Montana.

\section{Interrupting Movement}

Invasion is a function of seed dispersal and survival, site conditions, and the habitat requirements of the invading plant. Dispersal pathways are the mechanisms and routes by which weeds spread to new sites. Natural pathways include waterways, wildlife movement, and wind. Pathways associated with human activity generally allow invasive plants to establish at greater distances and at higher rates than natural dispersal. ${ }^{5}$

To reduce introductions, prevention measures in WPAs focus on the most important vectors and target weed spread as a factor of human activity. Human-related pathways in eastern Montana include transportation corridors, recreation, purposeful planting as ornamentals (e.g., saltcedar), and 
importation of contaminated materials, including soil, gravel, forage, and feed grains.

Transportation corridors. Roads, trails, and railways are primary pathways for new invaders, with vehicles or humans serving as the dispersal vectors. The continuously disturbed areas adjacent to roads and increased water from runoff can provide ideal habitat for weeds that establish and then invade nearby sites. Most new invaders to eastern Montana, such as spotted knapweed, colonize along roads and trails and then spread into adjacent grasslands. Other disturbance corridors are natural, as in the case of waterways, and also act as entry points for weeds into adjacent habitat.

The long-distance dispersal of weeds by vehicles has generated proposals to wash hunters' vehicles to reduce accidental weed introductions. But cleaning vehicles by normal car washing procedures-or at portable wash stations that can be economically expensive-might not entirely remove all the mud, debris, and seeds. A study on the importance of private vehicles as vectors of weed dispersal into protected areas found about three seeds per car were carried. ${ }^{6}$ Although more seeds might be picked up by vehicles that are driven through infestations, most seeds that dislodge will fail to establish. In WPAs, at-risk vehicles remain on roads and limited resources are prioritized to detect successful invasions along these pathways. ${ }^{6}$

Other transportation corridors, including ATV routes, can spread weeds deep into rangelands by dispersing seeds where they normally would not go and disturbing soil and vegetation. Cross-country travel with ATVs can increase the probability that weeds will spread into remote areas not normally monitored for weeds, allowing for uncontrolled colonization. WPAs restrict travel by ATVs to established roads and trails.

Because weeds do not stay confined to roadsides, minimizing the construction of new roads is a way to reduce invasions and prevent habitat loss and fragmentation. Habitat fragmented by roads has more edges than continuous habitat, negatively impacting the viability of native species for some distance from the edge and giving weeds an advantage over native species.

Recreation. Recreation visitors to eastern Montana include hunters, anglers, campers, hikers, bird watchers, and mountain bikers. Hunters from adjacent regions might be the most frequent recreationists to eastern Montana. Weeds can be accidentally transported over long distances from a contaminated area into the remote areas where they hunt. Hunters can reduce invasion risk by cleaning their boots, dogs, horses, and equipment, using weed-free forage or pelletized feed for pack animals, keeping all-terrain vehicles (ATVs) on roads and trails, and reporting invasions found in remote areas. ${ }^{7}$

Importation of Contaminated Materials. Although the use of weed-free materials is promoted, preventing all introductions is difficult because many goods are not certified. Building materials like timber and corrugated metal sheets containing spotted knapweed have been shipped from adjacent regions into eastern Montana. To avoid these contaminations, sites where at-risk materials are used are frequently monitored for invasions, clean-out areas for shipping trailers are checked, and weed-free livestock are maintained in WPAs to ensure safe movement between weed-free rangelands. Moving livestock from weedy areas into WPAs is avoided, but when necessary involves holding livestock in a designated pasture for about seven days prior to release into weed-free rangeland.

\section{Determining Site Susceptibility to Invasion}

Invasibility of plant communities, or the vulnerability of a site to invasion by a particular species, is site specific and determined by several interacting factors including the degree of disturbance, plant community structure, and propagule pressure-or the number and frequency of seeds arriving at a location from a particular weed adapted to the habitat. Grasslands can have high invasibility with respect to one plant (e.g., spotted knapweed or leafy spurge) and low invasibility with respect to others.

Disturbance can increase the rate of invader survival by creating empty niches or safe sites for germination and colonization and increasing the availability of limiting resources like nutrients, water, and light levels. Excessive grazing can increase resource availability to invaders by reducing the ability of desirable vegetation to uptake resources. Plant community structure, which is determined by the number, distribution, and abundance of plant species, can either protect communities against invasion or increase invasibility. ${ }^{8}$

Although disturbance and the structure of some plant communities can facilitate colonization, invasion success ultimately relies on the transport of seeds to a site. The areas most susceptible to invasion are those sites of human activity that increase propagule pressure and facilitate disturbance, ${ }^{9}$ including roads and trails, and waterways that are frequently disturbed and where seeds are transported by water. Other susceptible sites include the areas proximate to these pathways, and near disturbed sites and known infestations. ${ }^{10}$

Grasslands are inherently vulnerable to invasion due to resource and niche availability. But habitats distant from roads or intense human activity are likely at a lower risk of invasion because they are less disturbed and experience lower propagule pressure. Although some disturbance occurs on remote areas in the form of low to moderate grazing by wild ungulates and cattle, this is a natural disturbance inherent to eastern Montana grasslands. This near-natural disturbance supports the reproductive and growth potential of native grasses, and thus their competitive ability to utilize resources and suppress invasion. ${ }^{11}$ The most effective prevention strategy on interior rangelands includes minimizing weed dispersal, preventing excessive grazing, and monitoring to detect successful invasions.

High-risk sites. Roadsides and other vector pathways, campgrounds, and fishing-access sites in eastern Montana are at a high risk for invasion. These sites require additional attention because they can be exposed to multiple weed introductions and the vegetation at these sites is often disturbed. High risk sites include the following:

- Disturbance corridors: roads, hiking trails, railways, ATV routes, and waterways 
- Developed sites: campgrounds, trailheads, fishing-access sites, and hunter parking areas

- Areas near known seed sources

- Areas where at-risk material was used: forage, soil, gravel, etc.

- Areas visited by natural gas exploration equipment

- Livestock and wildlife trails, especially along fence lines, and areas of livestock concentration, including watering areas and salt licks

- Clean-out areas for livestock shipping trailers and

- Disturbed areas, particularly when located near pathways (e.g., utility corridors located near roads).

At high-risk sites, or those with the highest probability of new introductions, WPA managers extend surveys into areas beyond the weed entry point and anticipate repeated removal of new weeds over the long term.

\section{Mapping and Monitoring}

Prevention strategies are not perfect and only interrupt a portion of weed introductions. Proactive maintenance of weed-free rangelands therefore relies on continuous monitoring over time to detect successful invasions. This is critical, as new populations can spread quickly. Early detection surveys are based on invasibility.

Weed mapping includes both the inventory/survey and mapping processes and refers to a range of data capture and documentation. A weed inventory is a complete search of the WPA where every weed occurrence is documented, while a weed survey samples only a portion of the WPA.

After identifying search areas, mappers determine an effective detection swath width (EDSW) to ensure adequate coverage. The EDSW is the maximum sweep width along which mappers can identify the target weed. The sweep width varies based on terrain, vegetation community, and target visibility in relation to species, growth stage, and survey unit (plant vs. patch). Sweep widths range from 100 to 300 feet in grasslands and 50 to 75 feet in diverse vegetation. The EDSW is determined by identifying a representative target and then walking away from it as far as possible while still being confident of its detection, and then measuring the distance to the target and multiplying by two. ${ }^{12}$

Mappers require multiple sweeps to fully cover survey areas. After measuring the EDSW, line-transect surveys for stationary populations are performed using a census-based approach. Parallel transect lines, or search paths, are established in the survey area based on the associated EDSW. Two mappers are often deployed at the same time to shift positions. This rotates the lead and maintains mapper attention and concentration. Weed-free ATVs are used to search large areas in gentle, open terrain. Additional inventory and survey methods for invasive plants are described by Rew and Pokorny. ${ }^{13}$

Early detection surveys. Monitoring is performed during the peak flowering period, which varies by site and species, and focuses on the preferred habitat of the target weed. Surveys that target areas with a high likelihood of weeds are purposely biased. This is an effective approach when the objective is to locate invasions. Unbiased surveys that target areas at a lower risk of invasion-remote areas of low human activity-are also performed. Monitoring low-risk sites can locate weeds in unlikely areas and document weed-free rangelands to define a baseline for protection and comparison as WPAs progress over time.

A portion of new land area (about $5-10 \%$ ) in WPAs is surveyed each year. The land is re-checked every 5 to 10 years, depending on the likelihood of invasion by priority weeds. Ground surveys are recorded with global positioning system units. At a minimum, mappers record the date and the weed location and patch size. The entire search area is delineated, showing areas searched where weeds were found and areas that were weed-free. An estimate of the spatial and attribute accuracy accompanies the data, consisting of a simple text file describing data collection methods. The data are stored in centralized locations, such as county weed or geographic information system (GIS) departments.

High-risk sites are surveyed first, followed by other susceptible areas with less human activity, which are inspected annually during the flowering period of those weeds likely to invade. Low-risk sites, or large areas of least human visitation, are surveyed last to document weed-free areas and find remote weeds.

Passive monitoring. The WPAs have developed passive monitoring networks, made up of individuals who regularly access remote areas, including ranchers and hunters. These networks provide a framework for reporting invasions to weed departments. Call-to-action programs, for example, encourage hunters to report knapweed invasions to local weed departments (Fig. 3). Locations can also be reported at hunter check stations. Passive monitoring by hunters and other recreationists augments surveys that are performed by ranchers and weed departments.

Additionally, seasonal "weed scouts" are hired by weed departments and are often cost-shared by ranchers to expand surveys to private rangelands and assist with eradication. Weed scouts increase communication between ranchers and weed departments, and their personal contact with ranchers maximizes participation. They search for weeds on foot, horseback, or weed-free ATVs and report invasions to the landowner and the weed department.

Remote sensing. Ground surveys are the most accurate method to detect invasions, but they can be time and labor intensive. Traditional remote sensing technology collects vegetation data in the form of color and infrared aerial photography or satellite imaging. Remote sensing can map the distributions of some weeds when the weed color is distinct from the surrounding vegetation and the population is dense and widespread. However, remote sensing procedures can be time and processing intensive and often miss small infestations that are indistinguishable from the surrounding vegetation due to similar spectral reflectance.

Digital aerial sketch mapping (DASM) is a relatively new remote sensing technique that can provide quick interpretation of land features and early detection of weed 


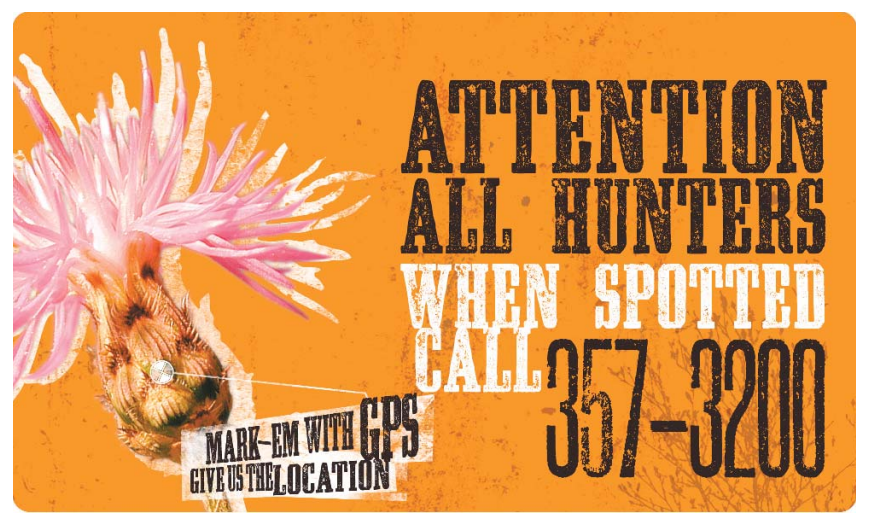

Figure 3. Call-to-action programs encourage hunters to report new invasions of spotted knapweed in eastern Montana to local weed departments.

populations in remote areas. Using light utility helicopters (e.g., Hughes 500 model) that can travel slowly (about 12 miles per hour) and close enough above the ground (about 50 feet), trained observers can visually discriminate weed patches in vegetation, even when the colors of both are similar, and map them with mobile GIS. DASM is a useful method to quickly and regularly search remote or inaccessible sites, especially near the advancing front of wind-dispersed plants having high survival rates, such as rush skeletonweed, which occupies regions adjacent to eastern Montana.

\section{Eradicating Invasions}

Eradication is the elimination of all reproducing individuals of a species. It can prevent future problems and slow the spread of weeds to new sites., ${ }^{5,14}$ A successful eradication is declared once the failure to detect individuals is equal to the longevity of the seed bank. Eradicating relatively large sites requires significant resource commitments over long periods of time due to the traits that make plants invasive in the first place. Extensive root systems, high reproduction rates, persistent seed banks, and effective dispersal can all hinder eradication.

Frequent site visits and herbicide treatments (and sometimes hand pulling) several times per year for many years can ensure plants do not reproduce by escaping detection and control. Locating every individual in a population depends on the conspicuousness of the weed in the surrounding vegetation. Detection rates also depend on surveyor experience, search effort, and method.

Applying control at an early stage of invasion will increase the likelihood of eradication and minimize total costs. ${ }^{15}$ Eradication costs are generally based on treatment area, site accessibility, ease of detection and control, and biological characteristics including seed longevity. Large infestations that can still be eliminated will demand adequate resources over time to exhaust soil seed banks, which can require decades of nearly perfect control. But detection becomes increasingly difficult as management reduces weed density over time.
As eradication progresses, increased monitoring is needed to maintain high levels of control. ${ }^{15}$ Detection dogs trained to search for and locate low-density weeds over large areas can increase the probability that inconspicuous plants will be detected. For instance, a recent study found that search dogs (Fig. 4) trained to detect the odor of spotted knapweed were more accurate $(67 \%)$ than human surveyors $(35 \%)$ at the critical detection of small adult plants (8 inches average height) and juvenile targets. ${ }^{16}$ Invasive plant monitoring using search dogs can improve detection rates and reduce operational costs associated with delayed extirpation.

\section{Evaluating Outcomes}

Assessing the effectiveness of prevention programs is challenging because it is difficult to measure dispersal and quantify invasion events that did not occur. We focus on short-term evaluation measures such as assessing the strategy designs of the WPAs that lead to preferred outcomes. For instance, we characterize a WPA as operating effectively when multiple proven strategies are implemented. WPAs operate ineffectively when gaps in implementation exist, allowing weed establishment and growth. Additional measures include stakeholder satisfaction, citizen engagement, and the number of partnerships formed among stakeholders at multiple levels. Although the number of invasions removed each year can provide a measure of the work accomplished, it gives little information on the effectiveness of the prevention system because it does not estimate the total introductions.

While the cost of prevention is paid in the present, its benefits lie in the future. Therefore long-term measures of success are optimal and include comparing future inventories to baselines to determine if strategies were effective over time. Prevention would be considered effective if high-risk sites remained weed-free and ineffective if new weeds establish and persist.

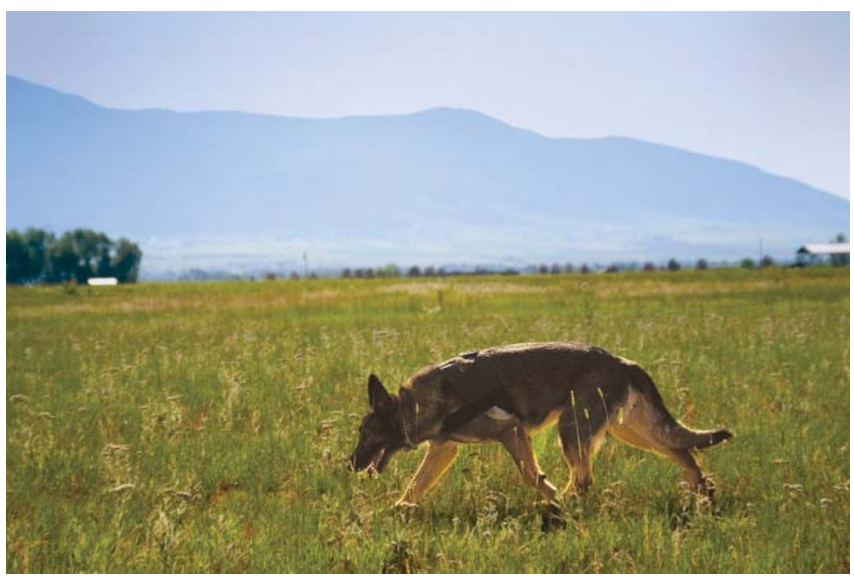

Figure 4. Search dogs can thoroughly cover large areas and detect obscure, low-density plants better than human surveyors. "Nightmare" searches for the odor of spotted knapweed in a dryland pasture near Bozeman, Montana. Photo: R. Gorsuch. 


\section{Keeping Lands Weed Free}

Weed prevention is a win-win situation for land managers and rangeland habitat. Cooperative prevention systems can preserve rangelands and lower the ultimate costs of weed management. Establishment of WPAs in eastern Montana has increased the awareness and knowledge of participants on the proactive maintenance of weed-free rangelands. Although weed prevention is a strong message, we reason significant social challenges exist as evidenced by a lack of public and policy concern on the long-term nature of the impacts of invasion. More specifically, citizens might not perceive invasions as an immediate threat because weed spread is a long-term phenomenon that builds gradually over time and does not produce a crisis or widespread response. Furthermore, people want quick and observable results, but the benefits of prevention are realized far into the future, and the results of prevention are not obvious.

Safeguarding weed-free rangelands is a protection of the public interest. Since weed prevention yields benefits that are a public good, it requires widespread support from the public, community action, and long-view investments to county weed departments for prevention and continuous monitoring over time. Future work includes incorporating principles of social marketing into prevention programs to refine weed spread as a crisis situation. Public support and policy will have lasting outcomes to secure necessary funding and prevention approaches which are optimal in the long term.

\section{Acknowledgments}

The authors acknowledge the support of Jeffrey Jacobsen, Dean and Director, College of Agriculture/Montana Agricultural Experiment Station at Montana State University (MSU), and the following MSU Extension Service agents and department heads: Larry Brence, Kent Williams, Gerald Marks, and David Bertelsen. Special thanks to Dale Veseth and Linda Poole and the following county weed coordinators: Jim Ghekerie, Terry Turner, Paul Wick, Ray Dolatta, Pete Pula, Paul Helland, and Jayme Wolfe. Thanks to Jeff Mosley, Mike Becker, Marjorie Smith, and anonymous reviewers for their helpful edits. We also thank The Nature Conservancy of Montana, the Montana Natural Heritage Program, and the Montana Fish, Wildlife and Parks Department.

\section{References}

1. Dukes, J. S., And H. A. Mooney. 2004. Disruption of ecosystem processes in western North America by invasive species. Revista Chilena de Historia Natural 77:411-437.

2. Wilcove, D. S., D. Rothstein, J. Dubow, A. Phillips, And E. Losos. 1998. Quantifying threats to imperiled species in the United States. BioScience 48:607-615.

3. DiTomaso, J. M. 2000. Invasive weeds in rangelands: species, impacts, and management. Weed Science 48:255-265.

4. Sheley, R. L. And J. K. Petroff [eds.]. 1999. Biology and management of noxious rangeland weeds. Corvallis, OR, USA: Oregon State University Press. 464 p.
5. Новвs, R. J., and S. E. Humphries. 1995. An integrated approach to the ecology and management of plant invasions. Conservation Biology 9:761-770.

6. Lonsdale, W. M., And A. M. Lane. 1994. Tourist vehicles as vectors of weed seeds in Kakadu National Park, Northern Australia. Biological Conservation 69:277-283.

7. Goodwin, K. 2008. Weed-free rangelands and wildlife habitat. Bozeman, MT, USA: Montana State University Extension. Extension Service Bulletin EB 4503. 2 p.

8. Levine, J. M., And C. M. D’Antonio. 1999. Elton revisited: a review of evidence linking diversity and invasibility. Oikos 87:15-26.

9. Lonsdale, W. M. 1999. Global patterns of plant invasions and the concept of invasibility. Ecology 80:1522-1536.

10. Davies, K. W., and R. L. Sheley. 2007. A conceptual framework for preventing the spatial dispersal of invasive plants. Weed Science 55:178-184.

11. Larson, L., M. McInnis, And G. Kiemnec. 1997. Rangeland weed invasion. Rangelands 19(3):30-32.

12. Dewey, S., and K. Andersen. 2006. Landscape-scale wildland inventories/surveys: Utah State University methods. In: L. J. Rew and M. L. Pokorny [EDs.]. Inventory and survey methods for nonindigenous plant species. Bozeman, MT, USA: Montana State University Extension. Extension Service Bulletin EB 171. p. 22-32.

13. Rew, L. J., And M. L. Pokorny [eds.]. 2006. Inventory and survey methods for nonindigenous plant species. Bozeman, MT, USA: Montana State University Extension. Extension Service Bulletin EB 4503.75 p.

14. Moody, M. E., And R. N. Mack. 1988. Controlling the spread of plant invasions: the importance of nascent foci. Journal of Applied Ecology 25:1009-1021.

15. Simberloff, D. 2003. Eradication-preventing invasions at the outset. Weed Science 51:247-253.

16. Goodwin, K. M., R. E. Engel, and D. K. Weaver. 2010. Trained dogs outperform human surveyors in the detection of rare spotted knapweed (Centaurea stoebe). Invasive Plant Science and Management 3:113-121.

Authors are Weed Prevention Coordinator, Center for Invasive Plant Management, Land Resources and Environmental Sciences Dept, Montana State University, Bozeman, MT 59717, USA, kgoodwin@montana.edu (Goodwin); Ecologist, USDA-Agricultural Research Service, Burns, OR 97720, USA (Sheley); Plant Materials Specialist, USDA-Natural Resources Conservation Service, Bozeman, MT 59715, USA (Jacobs); GIS/GPS Specialist, Land Resources and Environmental Sciences Dept, Montana State University, Bozeman, MT 59717, USA (Wood); Phillips County Extension Agent, PO Box 430, Malta, MT 59538, USA (Manoukian); Blaine County Extension Agent, PO Box 519, Chinook, MT 59523, USA (Schuldt); Garfield County Extension Agent, PO Box 81, Jordan, MT 59337, USA (Miller); and Prairie County Extension Agent, PO Box 7, Terry, MT 59349, USA (Sackman). Project funding was provided by the Center for Invasive Plant Management, National Fish and Wildlife Foundation, USDA-Natural Resources Conservation Service, and Western Region SARE. 